\title{
Logical Operations in Theory-Building Case Studies
}

\author{
WILLIAM B. STILES ${ }^{\text {a,b,c }}$ \\ ${ }^{\mathrm{a}}$ Department of Psychology, Miami University, Oxford, $\mathrm{OH}$ \\ b Correspondence concerning this article should be addressed to William B. Stiles, Department of Psychology, \\ Miami University, Oxford, OH 45056, USA. \\ E-mail: stileswb@muohio.edu

 \\ Mikael Leiman, James K. Mosher, Katerine Osatuke, David Rennie, Hugo J. Schielke, and Michael Westerman \\ for comments on drafts of this article.
}

\begin{abstract}
The logical operations involved in theory-building case studies include deduction (logical consistency and interconnection), induction (applying observations to theory), and abduction (creating, refining, and elaborating theory). The product of theory-building research is an account of a phenomenon in the form of words and other signs. Scientific quality control on theory is accomplished by comparing theoretical statements with observations. In case studies, detailed case observations are compared to detailed clinical theories. Stable meanings of terms and logical (deductive) interconnection allow empirical (inductive) observations on one tenet of a theory to affect confidence in other tenets. Researchers creatively modify their theories by (abductively) adding to them or altering them so that they correspond to accumulating observations. In this way, observations on cases permeate the theories, so that the words of the theory convey the accumulated experience of previous researchers.
\end{abstract}

Key words: logical operations; case studies; theory-building; assimilation model; deduction; induction; abduction.

\section{INTRODUCTION}

This paper is about the logic of using case studies to research and build theories. It reiterates points made previously (e.g., Stiles, 2003b, 2005, 2007, in press), but it adds new arguments, and it emphasizes the logical operations that are involved in theory-building. These include - in the order considered in this paper - deduction (logical consistency and interconnection), induction (applying observations to theory), and a less familiar one, abduction (creating, refining, and elaborating theory). Thus, the paper begins where most students begin, with the logic and evaluation of existing theories, while the abductive, constructive part of theory-building is addressed later in the paper.

Unlike clinical case studies, theory-building case studies do not aim primarily to gain a deeper understanding of a particular case, although a deep understanding is a valuable beginning. Clinical case studies may use multiple theories to aid understanding of the cases; 
the theories may point to phenomena that would not otherwise be noticed and suggest meanings that would not otherwise emerge, yielding a more diverse, richer perspective. Theory-building case studies, however, aim to build a single coherent theoretical account, one that is general, precise, and realistic. Although applying the theory to the case takes a first step in understanding the case, the point of the research is to apply case observations to the theory, to evaluate and improve it.

I have used case studies extensively in building a theory of psychological change that I and my collaborators have called the assimilation model (Stiles, 2002). It is a developmental account of therapeutic change (Leiman, 2004) that describes a regular sequence of stages through which people's problems pass in successful psychotherapy, along with processes that underlie it. A core strategy has been tracking problematic topics across psychotherapy sessions in intensive case studies, gradually elaborating a theoretical description of the observed change processes (e.g., Brinegar, Salvi, Stiles, \& Greenberg, 2006; Humphreys, Rubin, Knudson, \& Stiles, 2005; Leiman \& Stiles, 2001; Osatuke, Glick, Stiles, Greenberg, Shapiro, \& Barkham, 2005; Stiles et al., 2006). The ideas in this paper draw on my experience of researching the assimilation model. (More details about the process of developing the assimilation model can be found in a section titled, "Case Study Research on the Assimilation Model," on pages 7-9 of my article, "When is a Case Study Scientific Research?," published in the 2003 Psychotherapy Bulletin [Stiles, 2003b] and reproduced here with the journal's permission as Appendix A.)

\section{WHAT IS A THEORY?}

Scientific theories are descriptions of aspects of the world, such as how psychotherapy works, stated in words or numbers or diagrams or other signs. Scientific research provides quality control on theory by comparing these theoretical descriptions with observations. The theory is a good one if people's experiences of the theoretical descriptions (i.e., the meanings of the descriptions to them) correspond with their experiences of observing the objects and events in the world (or, conversely, if the descriptions of the events match the theories). I have elsewhere called this the experiential correspondence theory of truth (Stiles, 1981, 2006). The job of researchers, then, is to gather and describe appropriate observations, to see how well they match the theory.

Theories arise, I think, from people describing their observations of the world and then gradually revising the descriptions in light of further observations. Theories are important because they mediate the effect of scientific research on practice. Theories knit observations together, suggesting how observation of one thing may indicate that other things have taken place or will take place. Psychotherapy theories (e.g., psychodynamic, personcentered, cognitive-behavioral) are rich and detailed conceptual tools that psychotherapists use to understand their clients and guide their interventions (Leiman \& Stiles, 2002).

Theories are thus intensely practical. For better or worse, they organize therapists' experience of their clients, giving meaning and interconnection to the clients' past, present, and future. Whether and how one notices or challenges a depressed client's dysfunctional cognitions, or how one understands a slip of the tongue or a missed appointment, for 
example, must be creatively constructed in the moment based on theory. Thus, the quality of the theories therapists use can powerfully affect the quality of the treatment clients receive. Inaccurate, confused, or internally contradictory theories can lead to inappropriate, inefficient, or damaging treatment.

\section{HYPOTHESIS TESTING VERSUS CASE STUDY: CAMPBELL'S DEGREES OF FREEDOM ANALOGY}

Statistical hypothesis testing and case study are alternative strategies for empirical, scientific research on psychotherapy. Both provide quality control on theory by comparing theories with observations. They are, however, distinctly different strategies. Whereas a hypothesis-testing study addresses only one theory-derived statement or a few statements, a case study addresses many different theoretical statements in the same study.

As described in research methods textbooks, the statistical hypothesis testing strategy involves what has been called the hypothetico-deductive method. The scientist deduces one statement (or a few statements) from the theory and compares that statement with many observations. If the observations tend to match the statement (e.g., not due to chance, $\mathrm{p}<.05$ ), then the hypothesis is considered as confirmed, and confidence in the statement is substantially increased. This, inductively, yields a small increment of confidence in the theory.

Statistical hypothesis testing can be problematic for psychotherapy research. To achieve sufficient statistical power, research must study common features. That is, a single theory-derived statement (the hypothesis) must be relevant for all of the people being studied. Rare or unique features of cases cannot be studied comfortably and are too easily dismissed as irrelevant or as error. Common features of clinical cases, however, are often artificial (e.g., rating scale responses) or global (e.g., overall efficacy of a treatment) or trivial from a clinical perspective. Single statements (hypotheses) meant to apply across wide clinical contexts often seem pale and lifeless. Clinicians are likely to consider them as inadequate representations of their clinical theory and practice, which involves complex and diverse circumstances and contexts. As one consequence, results of statistical hypothesis-testing research often fail to interest clinicians (Talley, Strupp, \& Butler, 1994). More importantly, statistical hypothesis-testing results fail to address the richness and sensitivity to context that is present in clinical theories. Linear statistical models often fail to deal with the responsive interaction and recursive causality characteristic of psychotherapy (Stiles, Honos-Webb, \& Surko, 1998). Case studies, on the other hand offer the possibility of incorporating rich detail, clinical subtleties, contextual specificities, nonlinear relations, and developmental transformations.

In contrast to the statistical hypothesis-testing strategy, the theory-building case study strategy compares many theoretically-based statements with correspondingly many observations. It does this by describing case observations in theoretical terms. In essence, a case study asks how well the theory describes details of the case. Importantly, observations of a case may address different manifestations of a theoretical tenet or different tenets. For reasons familiar to researchers in psychology (selective sampling, low power, investigator 
biases, etc.), the change in confidence in any one statement may be small. However, because many statements are examined (describing different theory-relevant aspects or manifestations), the gain in confidence in the theory from a close match may be as large as from a statistical hypothesis-testing study. I attribute this argument to Campbell (1979), who suggested that the observations on multiple aspects of a case were analogous to the degrees of freedom in a statistical hypothesis-testing study.

I think that this argument moves case studies up in the hierarchy of evidence, at least for studying psychotherapy and other context-dependent, complex human phenomena. It suggests that case studies are appropriate in the context of justification, not just in the context of discovery.

The need for theory may seem more salient in case studies than in hypothesis-testing research because the entire burden of generalizing is borne by the theory. Isolated statements can gain little confidence from case studies because only one or a few relevant observations can be made. Any generality must proceed from changes in confidence in the theory as a whole.

\section{THEORETICAL STATEMENTS SHOULD BE LOGICALLY CONSISTENT AND INTERCONNECTED (DEDUCTION)}

Research - even case study research — can never address all the statements that could proceed from a theory. The rationale for doing any scientific research is that observations on one aspect of a theory can indirectly strengthen confidence in other aspects. This requires that the statements of the theory and statements derivable from the theory must be logically consistent, in the sense of not including direct contradictions. It also requires that the statements should be logically interconnected, in the sense that their logical truth values depend on each other. Otherwise, support for a hypothesis could not extend beyond the hypothesis itself. Similarly, case observations bearing on one part of a theory would have no bearing on other parts of the theory.

This process of inference is called deduction. I think it is helpful to distinguish two components of deduction as applied to psychological theory-building: formal rules of inference and fixed meanings for signs. First, at least since 350 BCE (Aristotle, 2007), scholars have recognized that verbal arguments can be evaluated by a system of formal rules. The elements of the argument and their relations can be cast as symbols, and sentences can be evaluated as to whether they meet requirements for valid inference. To illustrate:

If all $\mathrm{A}$ have quality $\mathrm{B}$, and $\mathrm{C}$ is an $\mathrm{A}$, then $\mathrm{C}$ has quality $\mathrm{B}$;

or more schematically,

$$
((\mathrm{A} \rightarrow \mathrm{B}) \& \mathrm{~A}) \rightarrow \mathrm{B} .
$$

In the classic syllogism,

All men are mortal (major premise).

Socrates is a man (minor premise).

Therefore, Socrates is mortal (consequent). 
Rules of inference in propositional logic can involve a variety of relations, including not only conjunction, disjunction, negation, implication, and equivalence, but also universal, existential, and uniqueness quantification. Logical propositions can become quite complex. Nevertheless, I think that the rules of inference are the easy part.

The second component of deductive logic is consistent sign meanings. I think this part is much more difficult for psychotherapy research than is following rules of inference. The problem is that, in formal logic, an inference does not remain valid unless the meanings of the terms remain fixed. If we conclude that $\mathrm{C}$ has quality $\mathrm{B}$, we cannot substitute new meanings for $\mathrm{B}$ and expect that $\mathrm{C}$ has it. Analogously, the logically (mathematically) derived relationship, $\mathrm{E}=\mathrm{mc}^{2}$, is not true for all $\mathrm{E}, \mathrm{m}$, and $\mathrm{c}$. We cannot decide that $\mathrm{E}$ now stands for elephant or for excitement level or even for energy measured in calories rather than Joules and expect the formula to remain valid.

Achieving stable meanings is problematic because, in natural language, signs continually change meaning, varying with context and audience and speaker's intent and many other things. Arguably, each use of a word means something slightly different to the author and to the addressee (Stiles, 1997, 1999). For example, you (hopefully) already understand something different by my use of the term logic than you did before you started reading this paper, and that meaning will change again many times before you finish reading. I intend (author's meaning) for the word to convey increasingly more of my thinking as this piece proceeds, requiring ever-greater shifts in the term's meaning for you (addressee's meaning).

Changing meanings interfere with logical inference. Consider, for example, that Socrates is actually immortal, alive and influential throughout Western scholarship through two and a half millennia. Does this well-known truth invalidate the classic syllogism? Not really. The verbal paradox arises because the meaning of Socrates and immortal changed from the flesh-and-blood man who drank a cup of poison hemlock and died to the enduring shared memory and cultural impact. The statement that Socrates is immortal makes perfectly good sense within natural language but not within the formal theory of human mortality.

In psychotherapy theory and research, natural language and theoretical uses are hard to separate and often confused. Such terms as transference, self-disclosure, and cognitivebehavioral therapy may mean many different things to different people at different times. Such variable meanings need not prevent clinical usefulness, as the terms can still convey previous clinicians' experiences; however, they can lead to internal contradictions in theoretical reasoning. If a theory is internally contradictory, evidence cannot strengthen it. Note that the problem is not the complexity or subtlety of these concepts, but rather the inconsistency across uses. In the physical sciences, term meanings are more stable, and measurement and quantification are more precise.

I think there is a widely-shared implicit understanding that, in theory-building, finding the right words is important, and much scientific discussion is occupied with seeking consistent meanings. I suspect that this need for stable terms helps explain scientists' attraction to numbers, which mean more or less the same thing to everybody (Stiles, 2006), 
and to basic units, simple objects, qualities, or events labeled unambiguously and stably. Whereas most informal human communication can be crafted for only one or a few particular addressees, scientific theories take all people as their addressees (or at least all who are adequately qualified) and seek a common understanding.

In the physical sciences, where theories are expressed mathematically (e.g., Einstein's special relativity theory was expressed using Laplace transformation equations), terminological and logical consistency are supplied by explicit definitions of mathematical symbols and mathematical rules of inference. Psychotherapy theories are seldom so tightly logically interconnected; that is, their statements are not deducible from axioms. Indeed, statements within psychotherapy theories are often logically unconnected. It seems reasonable to ask, however, that psychological theories be free of internal contradictions. In addition, psychological theories generally have some logical interconnections that permit observations on one statement to bear on confidence in other statements. I suggest it is desirable from a theory-building perspective to identify basic units and to construct and assess intermediate propositions that connect theoretical statements.

Psychological phenomena of interest to psychotherapists are typically developmental and historical, and they seem less subject to the sorts of (relatively) simple generalizations that describe physical phenomena. Physical theories deal with events and relations that seem somehow closer to basic units. Nevertheless, psychologists have principles that can be applied in lived contexts and can help people understand unique developmental and historical progressions.

As products of Western scholarship's strong tradition of evaluating the logic of arguments, most psychotherapy research journal reviewers and readers are alert for unjustified logical leaps. However, they can be fooled. As one major source of illogic, people have trouble distinguishing logical expectation from personal or cultural expectation. Confusing these can confound the first, inferential component of deductive logic because inferences are drawn from unstated commonsense presumptions rather than explicit theory. For example, at one of our lab meetings, in a discussion of how people react to trauma, one of our members said that it was logical that women who had been raped would often feel guilty and even self-destructive. What he meant, I think, is that this is a reasonable expectation, based on observations, and perhaps on empathy, that they often do feel this way. The expectation seemed coherent in the sense of narrative coherence (McAdams, 2006), which depends partly on listeners' psychological and cultural expectations and on their values and beliefs about what is normal or expectable. But is this self-destructive reaction logical in a formal sense? From what premises does this expectation flow? Conventional morality would suggest that the woman was not the wrongdoer and has no reason to feel guilty, much less any need to punish herself. From that conceptual perspective, the observation is a puzzle that requires explanation. It suggests that conventional morality is missing something important, that women's feelings about themselves after they have suffered this sort of trauma does not follow a simple moral calculus. The cultural or clinical sense that selfdestructive impulses are expectable among trauma victims hides the conceptual paradox and the need for theoretical explanation. (Trauma theorists have developed accounts that acknowledge this paradox; e.g., see Herman, 1992). 


\section{SIGNS AND MEANINGS}

People share experience through signs. When I say I walked through the green woods, to the extent that you understand me, you are sharing a bit of my experience of having walked in the woods. To the extent that you understand this article, you are experiencing some of my thinking about the logic of case studies. Likewise, through signs, such as the words used by therapists and clients, investigators can share, and in this sense observe and report, something of the experience of the people they investigate.

Signs are tangible and observable (in the world). The word green, for example, is a mark on a page or a screen or a vibration in the air. However, the meaning of the sign, as I use the term, is in someone's experience; it is the subjective process that goes with hearing, seeing, or speaking the sign. The meaning involves traces of other occasions and events previously experienced, shaped by context and by personal and cultural history. Green, for example, refers to the color of the woods in the spring, among many other things. Signs, then, are themselves part of reality, and they refer to other parts of reality (Leiman, 1992, 2002; Volosinov, 1986). In distinguishing the sign meaning from the physical sign and in saying that meaning is experiential, I am explaining how I use these terms. Others may use the terms meaning and sign differently. ${ }^{1}$

Sign meanings are generally different for author and addressee (people never understand each other perfectly) or for different addressees, and they are different at different times for the same person, as I noted earlier. Insofar as everyone's experience is always changing and signs represent that experience, sign meanings differ in each use. The word sign, for example, is changing and accumulating meaning, both for me and for you, as this section proceeds. How signs accumulate their meanings and how sign meanings are shaped in particular utterances are vast and complex topics, beyond the scope of this paper (see, e.g., Leiman, 2002; Stiles, 1997, 1999; Volosinov, 1986).

Insofar as theories are made of signs - words, numbers, diagrams, and so forth - they are public and observable. Theories must thus be distinguished from the meanings of theories - the ideas the theories express or convey. The meanings are private and cannot be directly observed by others.

Of course, theories are useful only insofar as they are understood; the point of theories is to convey to people a general, precise, and realistic conception of the world. As suggested earlier, the requirement for clear and stable meanings is at variance with natural language, so scientific theories demand special procedures and constraints.

\footnotetext{
${ }^{1}$ My conception of signs resembles and is descended from that of Volosinov (1986) and Leiman (2002). In their use of the term sign, however, they would include not only the external representation (e.g., a word written on a page), but also the referents and the meanings to the author and to the addressee as an indissoluble whole. I concur that every sign, in order to be a sign, has a referent and these meanings, but I find it more convenient to use separate terms to discuss the different aspects. Among other things, having separate terms makes it easier to talk about the observation that a particular sign, such the word sign in this instance, may have different meanings and referents for different people.
} 


\section{RESEARCH AIMS TO AFFIRM THE CONSEQUENT (INDUCTION)}

Scientific theories can never be fully confirmed, partly because they are composed of imperfect signs, but also because they concern events that have not yet happened. At best, research makes observations on specific instances covered by the theory and confirms their consistency with the theory. In terms of a formal syllogism, this amounts to affirming the consequent - a fallacy from the perspective of deductive logic. Observing that Socrates died affirms the consequent of the classic syllogism, but this is not logically sufficient to prove that all men are mortal.

Induction reasons that, nevertheless, affirming the consequent makes the major premise more plausible (in Bayesian terms, improves the posterior odds). For example, is higher.

After we observe that $\mathrm{C}$ is both $\mathrm{A}$ and $\mathrm{B}$ : our subjective probability that all $\mathrm{A}$ are $\mathrm{B}$

Socrates died, and this gives us marginally increased confidence that all men are mortal.

Progress can be made via multiple observations; after observing that several billion men have died and none has lived more than about 120 years, most people find the theory of men's universal mortality plausible, albeit still technically unproven. Expanding the premise and noting that men are a type of biological organism can make logically relevant the observations that not only several billion men but equally many women and uncounted numbers of other multicellular organisms have died. Embedding this in a more detailed theory of cellular vulnerability and senescence incorporates further observed details, such as the biological effects of the neurotoxic alkaloids in poison hemlock, and opens the prospect of avoiding, reversing, or at least postponing processes that lead to men dying.

As classically formulated, induction is the stuff of scientific research. This is quality control on ideas through seeking experiential correspondence between theory and observation. It is never final, but it can always continue to improve.

Importantly, the logic of induction presumes a formulated theory - a premise whose probability or plausibility is increased when the consequent is affirmed. The logic of induction is not one of gathering facts in the hope that truth will somehow emerge spontaneously.

Just as obeying the formal rules of inference in deduction is easier than finding stable terms, obeying the (probabilistic) rules of inference is the easy part of induction. Scientific research requires not only making observations but also, crucially, describing them, that is, sharing them with others via signs. Scientists must describe their methods and results so that readers of research reports share the essential aspects of scientists' experience. The descriptions of results must be precise and the terms must be stable for readers to make the necessary comparisons with the theoretical descriptions. Likewise, the process of gathering observations must be described in a way that can be replicated accurately and precisely, so stable, well-chosen words and other signs are needed to convey the method as well. 
As I understand it, objects, events, and qualities of the world (the things to which signs refer) cannot be known directly but only through the way people see, hear, feel, smell, or taste them or through their perceived effects on sensing instruments. Our experience of the world is thus as much a product of our own biological, psychological, and cultural makeup as of the objects and events that impinge on us. Because we cannot know the world directly, we construct and share descriptions and theories about it based on our experience of it.

Observers must find and adapt signs to share their experiences of the events. Further, each of us individually can observe only a tiny fraction of the world, even in this indirect way, so we depend on others to learn about it.

Although scientists themselves can compare theories with their perceptions of events, others can only compare theoretical statements with scientists' descriptions of events. These descriptions of events are not given by those events but require acts of creation by the observers.

Induction depends on the descriptions' accuracy, precision, and stability to be usefully compared with the (deduced) consequences of the theory. Thus, induction, like deduction, has to contend with the natural tendency of sign meanings to shift. It also has to contend with the capacity of human perception to be shaped by the perceiver's frame of reference - a capacity that often favors confirmation of observers' preferred theories. Scientists need to be able to understand clearly what others have observed as well as what the theory says, so there is a great need for signs that are unambiguous, in the sense that their meaning is the same for everyone, to the degree that this is feasible. As I suggested earlier, this need to say the same thing to everybody may explain why scientists go to such lengths to be precise and unambiguous in describing observations. And in particular, the remarkable capacity of numbers to mean the same thing across people and time may explain why scientists are so enamored of statistical and mathematical descriptions (Stiles, 2006).

\section{UNIQUE FEATURES OF CASES CAN INFORM THEORY}

Psychotherapy theories are meant to encompass more than is ever encountered in a single case. Each case includes details not shared with other cases, and a good clinical theory helps practitioners understand the variations as well as the common features. Conversely, unexpected distinctive features of cases can show where theories need to grow. Unlike statistical hypothesis testing, where rare or unique features may be regarded as error, case studies allow researchers to incorporate them into research and theory (Stiles, 2003b, 2005, 2007). I have drawn this point from Rosenwald's (1988) theory of multiple case study research, where he argued that an adequate understanding of a social phenomenon must encompass its varied manifestations in different people.

I think this point is the one made by the parable of the six blind men and the elephant. The man who felt its side said the elephant was like a wall; the man who felt its tusk, like a spear; the man who felt its trunk, like a snake, and so forth. Each inference was different, but all of the inferences were at least partly justified and all described the same animal. Although the blind men in the parable failed to listen to each other, the point is that the elephant has many aspects, just as psychotherapy encompasses many different cases. An adequate theory 
has to incorporate the distinct features of each case as well as the common features. More concretely, it is not necessary to observe the same variables in every case. On the contrary, restricting attention to the themes that are common across cases will miss the most interesting parts. Each case tells us something new, and new observations are always valuable, whether they confirm previous theory or reveal something unexpected.

Thus, case studies can turn distinctive human experience and behavior into data, making it possible to study the richness of such phenomena as friendship, play, and imagination. People's experience is observed, through signs, when investigators understand what the people say and see what they do. Likewise, case studies can bring contextually specific features into theory. By observing and describing the details of what particular individuals say and do and experience - and when they say, do, or experience it - case studies can address theories in ways denied to statistical hypothesis testing, which is restricted to phenomena that can be quantified and counted and observed in frequencies large enough for inferential comparisons.

Through case studies, then, the richness of empathy with another human being can be registered, and inhuman or mechanical theories can be challenged. The experiences investigators share with participants in their research can also be shared with readers and brought to bear on theory. Through case studies, investigators can build theories that accommodate rich and empathic observations of people.

\section{OBSERVATIONS PERMEATE THEORIES (ABDUCTION)}

Even though scientific theories cannot be proven, they can be falsified, a logical asymmetry usually associated with Popper (1959). If the theory holds that all men are mortal and Socrates is immortal, then the theory of universal human mortality cannot be true. In practice, contrary findings do not lead scientists to abandon their theories, however, at least in the human sciences (Lakatos, 1978; Meehl, 1990). Instead, faced with contrary evidence, scientists first check methods and ancillary conditions. If, after replicating with corrected methods and appropriate conditions, repeated observations still seem not to match, they may abandon the theory. More often, however, they modify the theory so that the observations do match it.

The American philosopher Charles Sanders Peirce (1839-1914) used the term abduction to describe the logical operation of creating new tenets for scientific theories (Peirce, 1931-1958; Rennie, 2000; Peirce also used the terms retroduction and hypothesis for the same concept at various points in his career). Abduction responds to a new or unexpected observation by creating a tenet such that, if the new tenet were the case, then the observation would be expected. Abduction thus describes the operation of constructing a new hypothesis or of explaining new observations within a theory. It is the only one of the three logical operations (deduction, induction, and abduction) through which new elements can enter a 
W.B. Stiles

Pragmatic Case Studies in Psychotherapy, http://pcsp.libraries.rutgers.edu

Volume 5, Module 3, Article 2, pp. 9-22, 09-12-09 [copyright by author]

theoretical understanding. ${ }^{2}$ Abduction proceeds by reasoning:

If $\mathrm{A}$ were true, observations, $\mathrm{B}_{1}, \mathrm{~B}_{2}$, and $\mathrm{B}_{3}$ would be among the consequences.

We observe $\mathrm{B}_{1}, \mathrm{~B}_{2}$, and $\mathrm{B}_{3}$. Therefore, we can provisionally incorporate $\mathrm{A}$ into our theory.

Thus, through successful abductions, a theory can expand to encompass ever more new and unexpected observations. In particular, the rich observations of case studies can be used to build theories. In principle, the theory must be reconciled with observations of each new case; any relevant observation may be an occasion for adding or adjusting tenets.

I emphasize that abduction does not have free rein. A newly created theoretical tenet is constrained by the terms in which the new observation is described, by the existing theory, and by previous observations that the theory had incorporated. That is, first, to be useful, an abduction must be germane, in the sense that its terms must characterize the new observation in a way that logically connects it within the structure of the theory (this is what we mean by explanation, I think). Second, except for those parts of the existing theory that it explicitly alters, the new abduction must be logically consistent with the rest of the theory in the sense discussed earlier (no internal contradictions, consistent meanings for terms). And third, the altered theory must continue to explain (to be logically consistent with the descriptions of) the observations previously explained by the theory.

Abduction thus starts with a meaningful account and modifies it. The modifications may include corrections of previous errors, elaborations of previously unappreciated aspects, or extensions to domains not previously encompassed. Theory building can be continual, in response to each new observation, and logical consistency is assessed continuously. New tenets may require adjustments in other parts of the prior theory (sometimes major adjustments) in order to maintain logical consistency and consistency with previous observations. The altered theory should convey the new research observations to others without obscuring what previous researchers have observed. Of course, labeling this process as abduction does not explain how researchers creatively construct new theoretical tenets.

I like to describe this process of abduction as research observations permeating the theory (Stiles, 1993, 2003a). This invokes a diffusion metaphor: particles of observation spread through the theoretical interstices. Through abduction, theories change to fit new observations. In a sense, then, aspects of the observations become part of the theory, in the form of new or altered tenets or illustrative examples.

${ }^{2}$ Peirce further suggested that abduction is the psychological process by which new descriptions come into being. In effect, putting any observation into words brings it into a personal theory of the world.

All that makes knowledge applicable comes to us viâ abduction. Looking out of my window this lovely spring morning I see an azalea in full bloom. No, no! I do not see that; though that is the only way I can describe what I see. That is a proposition, a sentence, a fact; but what I perceive is not proposition, sentence, fact, but only an image, which I make intelligible in part by means of a statement of fact. This statement is abstract; but what I see is concrete. I perform an abduction when I so much as express in a sentence anything I see. (Peirce, 1985, pp. 899-900, italics in original) 
Through abduction, observations accumulate in theories. New research results including case observations - permeate the theory, while earlier thinking and results are retained. The diffusion metaphor is an alternative to the brick wall metaphor for how science is cumulative. Theories grow not by building an edifice, piling fact on fact, but by infusing observations that elaborate and change the theory. The theory thus conveys, in the form of signs, the accumulated observations of those who have researched it. When we understand a theory, we experience an aggregate of what previous investigators experienced.

\section{SUMMARY}

To summarize my argument: The product of theory-building research is an account of a phenomenon in the form of signs. Theories are clinically important. Scientific quality control on theory is accomplished by comparing theoretical statements with observations. In case studies, detailed case observations are compared to detailed clinical theories (Campbell, 1979), incorporating unique as well as common aspects of cases (Rosenwald, 1988). In order to benefit from research, theories must be logically internally consistent and interconnected, which requires conformity with formal (deductive) rules of inference, links between assertions, and stable meanings for the theoretical terms. Stable meanings and logical interconnection allow empirical (inductive) observations on one tenet of a theory to affect confidence in other tenets. When the observations fail to match the theory (or, more precisely, when researchers' experience of the observations fails to correspond to their experience of the theory), even after methodological checks, researchers may creatively (abductively) modify the theory by adding to it or altering it so that it does match (Peirce, 1965). In this way, observations on cases permeate the theories so that the words of the theory convey the accumulated experience of previous researchers to new researchers and to practitioners.

Both hypothesis-testing research and case studies use deduction to ensure that the theory is internally consistent and interconnected - so that observations on one part have a bearing on other parts. Both use induction, turning observations into descriptions and comparing these with theory to assess the theory's plausibility. And, when observations don't match the theory or exceeds the theory's prior limits, both strategies can use abduction to correct, extend, or elaborate the theory.

The argument underlines the importance of permeability. Theories must grow and change to reflect new observations while remaining consistent with previous observations. When theories become impermeable, for example, when the word of the master is trusted to the point of ignoring new observations, they gradually become outmoded.

\section{REFERENCES}

Aristotle (2007). Prior analytics (A. J. Jenkinson, Trans.). Adelaide, Australia: eBooks@Adelaide. (original work published approx.350 BCE). (http://etext.library.adelaide.edu.au/a/aristotle/a8pra/ updated April 5, 2007).

Brinegar, M. G., Salvi, L. M., Stiles, W. B., \& Greenberg, L. S. (2006). Building a meaning bridge: Therapeutic progress from problem formulation to understanding. Journal of 
Counseling Psychology, 53, 165-180.

Campbell, D. T. (1979). "Degrees of freedom" and the case study. In T. D. Cook \& C. S. Reichardt (Eds.), Qualitative and quantitative methods in evaluation research (pp. 49-67). Beverley Hills, CA: Sage.

Herman, J. (1992). Trauma and recovery. New York: Basic Books.

Humphreys, C. L., Rubin, J. S., Knudson, R. M., \& Stiles. W. B. (2005). The assimilation of anger in a case of dissociative identity disorder. Counselling Psychology Quarterly, $18,121-132$.

Lakatos, I. (1978). The methodology of scientific research programs. Cambridge, England: Cambridge University Press.

Leiman, M. (1992). The concept of sign in the work of Vygotsky, Winnicott and Bakhtin: Further integration of object relations theory and activity theory. British Journal of Medical Psychology, 65, 209-221.

Leiman, M. (2002). Toward semiotic dialogism. Theory and Psychology, 12, 221-235.

Leiman, M. (2004). Vaikuttavuustutkimuksen pulmallisuus psykoterapiatutkimuksessa [Problems of efficacy studies in psychotherapy research]. Duodecim, 120, 2645-2653.

Leiman, M., \& Stiles, W. B. (2001). Dialogical sequence analysis and the zone of proximal development as conceptual enhancements to the assimilation model: The case of Jan revisited. Psychotherapy Research, 11, 311-330.

Leiman, M., \& Stiles, W. B. (2002). Integration of theory: Methodological issues. In I. Säfvestad-Nolan \& P. Nolan (Eds.), Object relations and integrative psychotherapy: Tradition and innovation in theory and practice (pp. 68-79). London: Whurr Publishers.

McAdams, D. P. (2006). The problem of narrative coherence. Journal of Constructivist Psychology, 19, 109-125.

Meehl, P. E. (1990). Appraising and amending theories: The strategy of Lakatosian defense and two principles that warrant it. Psychological Inquiry, 1, 108-141.

Osatuke, K., Glick, M. J., Stiles, W. B., Greenberg, L. S., Shapiro, D. A., \& Barkham, M. (2005). Temporal patterns of improvement in client-centred therapy and cognitivebehaviour therapy. Counselling Psychology Quarterly, 18, 95-108.

Peirce, C. S. (1931-1958). The collected papers of Charles Sanders Peirce (Vol. 1-8; C. Hartshorne, P. Weiss, \& A. Burks, Eds.). Cambridge, MA: Harvard University Press.

Pierce, C. S. (1985). The proper treatment of hypotheses: A preliminary chapter, toward an examination of Hume's argument against miracles, in its logic and in its history. In C. Eisele (Ed.), Historical Perspectives on Peirce's Logic of Science. A History of Science, Vol. 2. Berlin: Mouton Publishers.

Popper, K. (1959). The logic of scientific discovery. New York: Basic Books. (Original work published 1934).

Rennie, D. L. (2000). Grounded theory methodology as methodological hermeneutics: Reconciling realism and relativism. Theory \& Psychology, 10, 481-502.

Rosenwald, G. C. (1988). A theory of multiple case research. Journal of Personality, 56, 239-264.

Stiles, W. B. (1981). Science, experience, and truth: A conversation with myself. Teaching of Psychology, 8, 227-230.

Stiles, W. B. (1993). Quality control in qualitative research. Clinical Psychology Review, 13, 
593-618.

Stiles, W. B. (1997). Signs and voices: Joining a conversation in progress. British Journal of Medical Psychology, 70, 169-176.

Stiles, W. B. (1999). Signs and voices in psychotherapy. Psychotherapy Research, 9, 1-21.

Stiles, W. B. (2002). Assimilation of problematic experiences. In J. C. Norcross (Ed.), Psychotherapy relationships that work: Therapist contributions and responsiveness to patients (pp. 357-365). New York: Oxford University Press.

Stiles, W. B. (2003a). Qualitative research: Evaluating the process and the product. In S. P. Llewelyn \& P. Kennedy (Eds.), Handbook of Clinical Health Psychology (pp. 477499). London: Wiley.

Stiles, W. B. (2003b). When is a case study scientific research? Psychotherapy Bulletin, 38(1), 6-11. [reprinted as Appendix A in Stiles, 2009].

Stiles, W. B. (2005). Case studies. In J. C. Norcross, L. E. Beutler, \& R. F. Levant (Eds.), Evidence-based practices in mental health: Debate and dialogue on the fundamental questions (pp. 57-64). Washington, DC: American Psychological Association.

Stiles, W. B. (2006). Numbers can be enriching. New Ideas in Psychology, 24, 252-262.

Stiles, W. B. (2007). Theory-building case studies of counselling and psychotherapy. Counselling and Psychotherapy Research, 7, 122-127.

Stiles, W. B. (in press). Theory-building case studies as practice-based evidence. In M. Barkham, G. Hardy, \& J. Mellor-Clark (Eds.), Developing and delivering practicebased evidence in the psychological therapies. Chichester, UK: Wiley.

Stiles, W. B., Honos-Webb, L., \& Surko, M. (1998). Responsiveness in psychotherapy. Clinical Psychology: Science and Practice, 5, 439-458.

Stiles, W. B., Leiman, M., Shapiro, D. A., Hardy, G. E., Barkham, M., Detert, N. B., \& Llewelyn, S. P. (2006). What does the first exchange tell? Dialogical sequence analysis and assimilation in very brief therapy. Psychotherapy Research, 16, 408-421.

Talley, P. F., Strupp, H. H., \& Butler, S. F. (Eds.) (1994). Psychotherapy research and practice: Bridging the gap. New York: Basic Books.

Volosinov, V. N. (1986). Marxism and the philosophy of language. Cambridge, MA: Harvard University Press.

\section{NOTE: Appendix A follows. This is a reprint of Stiles (2003b). We thank the Psychotherapy Bulletin for permission to republish this article.}




\section{PSYCHOTHERAPY BULLETIN}

Published by the

DIVISION OF

PSYCHOTHERAPY

American Psychological Association

6557 E. Riverdale

Mesa, AZ 85215

602-363-9211

e-mail: assnmgmt1@cox.net

EDITOR

Linda Campbell, Ph.D.

\section{CONTRIBUTING EDITORS}

Washington Scene

Patrick DeLeon, Ph.D.

Practitioner Report

Ronald F. Levant, Ed.D.

Education and Training Corner Jeffrey A. Hayes, Ph.D.

Professional Liability

Leon VandeCreek, Ph.D.

Finance

Jack Wiggins, Ph.D.

For The Children

Sheila Eyberg, Ph.D.

Psychotherapy Research

Clara E. Hill, Ph.D.

\section{Student Corner}

Anna McCarthy

STAFF

Central Office Administrator Tracey Martin

\section{PSYCHOTHERAPY BULLETIN}

Official Publication of Division 29 of the American Psychological Association

\section{Volume 38, Number 1 Spring 2003}

\section{CONTENTS}

President's Column .....................................................

Student Column ..........................................................

Research Corner .........................................................

Feature: The Added Value of RxP Training ......12

APA Council Report ................................................15

Division 29 Social Hour ...........................................16

Practitioner Report ................................................17

Division 29 Member Gathering ............................20

Feature: In Conversation with

Dr. Al Mahrer .21

Division 29 Mid-Winter Meeting .25

Feature: Clinical Coaching: A Paradigm for Supervision

Candidate Statements .30

Feature: The Unseen Diagnosis:

Addiction Assessment

Call for Nominations: Editor of

Psychotherapy Bulletin

Free Division of Psychotherapy Continuing

Education Workshop at APA Convention .......44

Feature: Was the Competencies

Conference 2002 a Competent

Conference

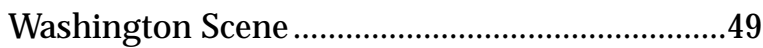

Call for Papers ...........................................................55

APA Membership Application ..............................56 


\title{
When is a Case Study Scientific Research?
}

\author{
William B. Stiles \\ Miami University
}

William B. Stiles is a professor of clinical psychology at Miami University in Oxford, Ohio. $\mathrm{He}$ is a psychotherapy researcher and a psychotherapist. He received his Ph.D. from UCLA in 1972. He taught previously at the University of North Carolina at Chapel Hill, and he has held visiting positions at the Universities of Sheffield and Leeds in England, at Massey University in New Zealand, and at the University of Joensuu in Finland. He is the author of Describing Talk: A Taxonomy of Verbal Response Modes. He is a past president of the Society for Psychotherapy Research, and he is currently North American Editor of Psychotherapy Research.

Author Note: I thank Meredith J. Glick, Michael A. Gray, Carol L. Humphreys, Katerine Osatuke, and Lisa M. Salvi for comments on drafts of this article. Correspondence should be addressed to William B. Stiles, Department of Psychology, Miami University, Oxford, OH 45056. Fax 1-513-529-2420. Email stileswb@muohio.edu.

I propose this answer to the title question: When observations of the case are explicitly brought to bear on a theory. I will first try to describe briefly what I mean by scientific research and how case studies can fit the description. Then, as an illustration, I will describe the assimilation model, a theory of how people change in therapy (Stiles, 2001, 2002; Stiles et al., 1990), and give some examples of how case studies have been brought to bear on it.

In this article, I focus on the scientific purposes of case studies. I acknowledge, however, that case studies may be interesting or enriching independently of their contribution to scientific theory (Stiles, in press).
WHAT I MEAN BY SCIENTIFIC RESEARCH Scientific research compares ideas with observations. In good research, the ideas are thereby changed. The observations may be said to permeate the ideas (Stiles, 1993, in press): Sometimes the observations simply confirm or disconfirm the ideas and make them stronger or weaker. More often, the observations lead to extensions, elaborations, modifications, or qualifications of the ideas. The ideas change to better fit the observations; in effect, aspects or qualities of the observations become part of the ideas. Science is cumulative because observations permeate ideas in this way.

Theories are ideas stated in words (or numbers or diagrams or other signs), which communicate ideas between peoplebetween author and reader in the case of research reports. To the extent that communication is successful, the reader experiences something similar to the author's understanding. Empirical truth-the goal toward which theoretical statements strive-can be understood as a correspondence between theories and observed events. Of course, it is a nonsense to suppose that the words in a theory (e.g., print on a page, spoken sounds) literally correspond to the concrete objects or events described. However, both the words and the events are experienced by people; that is, they produce ideas and observations. Because both of these are human experiences-composed of the same stuff-they can be compared and judged as similar or different (Stiles, 1981).

Empirical truth is never general or permanent because different people experience words and events differently, depending on their biological equipment, culture, life history, and current circumstances. 
Nevertheless, it is often possible to distinguish better from worse theories or decide which parts of theories need changing, based on their experienced correspondence with events. As new observations permeate at theory, the theory changes to better match the observations. For example, the theory may be explained differently, using different words or perhaps using the new observations as illustrations.

To summarize my view: Theory can be considered as the principal product of science. The work of scientists can be considered as quality control, insuring that the theories are good ones by comparing them with observations. Good theories are useful. By accurately representing the process of psychotherapy, for example, a good theory can help practitioners understand their clients and how to be effective in helping them.

\section{TESTING THEORIES WITH CASE STUDIES}

In contrast to statistical hypothesis-testing research, case studies characteristically yield results mainly in words rather than numbers, use empathy and personal understanding rather than detached observation, place observations in context rather than in isolation, focus on good examples rather than representative samples, and sometimes seek to empower participants rather than merely to observe them (Stiles, 1993, in press). I suggest that case studies, as well as statistical hypothesis-testing research, can permeate scientific theory and contribute to quality control.

In statistical hypothesis-testing research, an investigator extracts or derives one statement (or a few statements) from a theory and attempts to compare this statement with a large number of observations. If the observed events tend to match the derived statement (that is, if the scientists' experience of the observations resembles their experience of the statement), then people's confidence in the statement is substantially increased, and this, in turn, yields a small increment of confidence in the theory as a whole.
In a case study, instead of trying to assign a firm confidence level to a particular derived statement, an investigator simultaneously compares a large number of observations based on a particular individual with a correspondingly large number of theoretically-based statements. Each statement that describes some aspect of the case in theoretical terms represents a comparison of the theory with an observation. At issue is how well the theory describes the details of the case. For a variety of familiar reasons (selective sampling, low power, potential investigator biases, etc.), the increase (or decrease) in confidence in any one theoretical statement may be very small. That is, isolated descriptive statements drawn from a case study can't be confidently generalized. Nevertheless, because many statements are examined, the increase (or decrease) in confidence in the theory may be comparable to that stemming from a statistical hypothesis-testing study. A few systematically analyzed cases that match a theory in precise or unexpected detail may give people considerable confidence in the theory as a whole, even though each component assertion may remain tentative and uncertain when considered separately. I think the most convincing support for the assimilation model has been the detailed fit between the model and observations in a series of intensive case studies (e.g., Honos-Webb, Stiles, Greenberg, \& Goldman, 1998; Knobloch, Endres, Stiles, \& Silberschatz, 2001; Stiles, 1999b; Stiles, Meshot, Anderson, \& Sloan, 1992; Stiles et al., 1991; Varvin \& Stiles, 1999).

\section{CASE STUDY RESEARCH ON THE ASSIMILATION MODEL}

At the core of the assimilation model is an observational strategy: identifying problems and tracking them across sessions, using tape recordings or transcripts (Stiles, 2001, 2002; Stiles \& Angus, 2001). Drawing cases from a variety of therapeutic approaches, we have observed how expressions of a problem differ from time to time, we have inferred a process of change, and 
we have developed concepts to describe this process.

According to the model, people's experience leaves traces, which can be re-activated by events that have related meanings. That is, thoughts, feelings, and actions, tend to re-emerge in related circumstances, and they then be come linked to the traces of the new experiences. As a result, traces of related experiences occurring at different times tend to form interlinked constellations, providing the experiences are unproblematic. We call the traces of experience voices to emphasize that they are active agents, which can act and speak (Honos-Webb \& Stiles, 1999; Stiles, 1997, 1999a, 2002). The process of interlinking is called assimilation. Assimilated voices serve as a repertoire of resources, drawn upon to deal with life's demands. For example, cooking skills (traces of previous cooking experiences) tend to emerge, appropriately, in the kitchen.

Some experiences are problematic, however, for example, traumatic events or destructive important relationships. The problematic traces, or voices, are not smoothly integrated, but are treated as unwelcome or foreign. Triggering them is signaled by negative emotion. Psychotherapy, according to the assimilation model, is a process of turning such problematic experiences into resources. For example, in one case (Debbie; Stiles, 1999b), an angry, rejecting voice that was responsible for violent verbal and physical outbursts was assimilated and gradually transformed into a capacity for appropriate assertiveness.

On their way to becoming resources in successful therapy, problematic experiences appear to pass through a sequence of stages or levels of assimilation, described in the Assimilation of Problematic Experiences Scale (APES). As shown in Table 1, the APES includes 8 levels numbered 0 through 7. Applied to passages from therapy, each APES rating character- izes the degree of assimilation of particular problematic content. The names of the levels describe the state of the problematic voice (traces of a problematic experience) from the viewpoint of the community. In case studies, the APES has typically been used not by independent raters but by investigators who have used APES ratings to precisely convey their context-informed assessment of each problem's degree of assimilation. Using assimilation analysis (Stiles \& Angus, 2001; Stiles \& Osatuke, 2000), investigators become familiar with a case, identify a problematic voice, excerpt passages representing that voice, and then use the APES to help describe whether and how it was assimilated. The APES is a summary of our current understanding of the sequential process of assimilation, and the scale continues to evolve.

Although there have been some statistical hypothesis-testing studies addressing the assimilation model (see Stiles, 2002, for a review), the model has grown mainly from the case studies (e.g., Honos-Webb et al., 1998; Knobloch et al., 2001; Stiles, 1999b; Stiles et al., 1990, 1991, 1992; Varvin \& Stiles, 1999). The gradual development of the APES illustrates how the case observations have permeated the model, refining, elaborating, and clarifying it:

The development of the APES began with a list of immediate therapeutic impacts (Stiles et al., 1991), which were derived from clients' open-ended descriptions of helpful and unhelpful events within therapy sessions (Elliott, 1985; Elliott et al., 1985). Based on our initial case observations, we listed the impacts in sequence to reflect our understanding of the assimilation process, and we modified and expanded the impact descriptions to construct the anchored eight-point scale. As an example of modification and expansion, although the original "personal insight" impact category was characterized as a "task impact" (Elliott et al., 1985, p. 622), we observed that therapeutic insight events were accompanied by intense but mixed (posi- 
tive and negative) emotion in the first cases we studied (Elliott et al., 1994; Stiles et al., 1990). Consequently, we included affective features in our characterization of APES level 4, understanding/insight (see Table 1). As another example, although APES level 2 was originally called simply "vague awareness" (Stiles et al., 1991, p. 199), even early case studies showed a quality of emergence at this level (e.g., describing the case of Joan at APES level 2: "the intense psychological pain signaled the emergence of the unwanted thoughts"; Stiles, 1991, p. 202). As this pattern was repeated across cases, the term emergence was eventually added to the name and description of level 2 (see Table 1).

If a case fits the theory in a great many respects but fails to fit it in a small and specific way, this can point to something in the theory that needs changing, as in the following example: In the earlier versions of the APES (e.g., Honos-Webb et al., 1998; Stiles et al., 1991, 1992), which were based mainly on studies of depressed but otherwise well-functioning clients, the APES level 0 was called simply warded off. More recently, in considering cases with borderline features, we observed material that was clearly problematic and unassimilated but not warded off. On the contrary, these unassimilated voices emerged all too forcefully in state switches, in effect, taking over the person. Despite this discrepancy, there were many aspects of these cases that fit the model's account well. For example, the opposing states were at first mutually inaccessible, encounters between them tended to be emotionally painful, and in successful therapy, they seemed to go through the sequence described in Table 1 . Thus, the observations did not justify abandoning the theory, but instead led to some alterations (e.g., Osatuke \& Stiles, in preparation, Stiles, 2002), such as the addition of the term "dissociated" in the label of APES level 0 and rewriting of the level 0 description (Table 1). This reformulation also offered an improved fit with dissociated traumatic experiences, which, when trig- gered, may emerge in flashback phenomena, such as film-like reliving of the trauma (Varvin \& Stiles, 1999). Thus, the alteration based on new case observations strengthened the model.

\section{SOME IMPLICATIONS}

In summary, I suggest that case studies offer an alternative that can complement hypothesis-testing research. By simultaneously bringing many observations to bear on a theory, case studies offer both a way to test and an opportunity to improve the theory. I acknowledge that other people may mean something by scientific research besides comparing ideas with observations. My meaning implies that, for example, Freud's case studies, such as Dora (Freud, 1905/1953) and Schreiber (Freud, 1911/1958) qualify as scientific research. In my view, Freud's case studies permeated psychoanalytic theory (that is, the theory was altered by them), and the detailed fit between the theory and the cases helped increase confidence in the theory. In the same way, our assimilation case studies have both changed the assimilation model and built our confidence in it.

An implication of my argument is that case study authors can make their research scientific by articulating their case's detailed relation to an explicit theory. In principle, this could be a new theory, developed from the case at hand, as long ago suggested in the grounded theory approach (Glaser \& Strauss, 1967). Arguably, psychoanalysis and many other theories of therapy began as accounts of cases. Constructing a new theory for each case, however, forgoes the benefits of cumulative improvements, and fewer readers may be interested in a theory developed for one-time use.

Of course, neither Dora, nor Schreiber, nor the assimilation case studies, nor any single piece of scientific research-case study or otherwise-can overcome all the ambiguities and doubts in a theory. Like other theories, the assimilation model is far from a precise or complete account; I hope and 
expect it will continue to be permeated by observations on new cases. All good scientific theories, I believe, remain open-ended, stimulating new research while they accumulate, summarize, and convey previous observations.

\section{REFERENCES}

Elliott, R. (1985). Helpful and nonhelpful events in brief counseling interviews: An empirical taxonomy. Journal of Counseling Psychology, 32, 307-322.

Elliott, R., James, E., Reimschuessel, C., Cislo, D., \& Sack, N. (1985). Significant events and the analysis of immediate therapeutic impacts. Psychotherapy, 22, 620-630.

Elliott, R., Shapiro, D. A., Firth-Cozens, J., Stiles, W. B., Hardy, G. E., Llewelyn, S. P., \& Margison, F. R. (1994). Comprehensive process analysis of insight events in cognitive-behavioral and psychodynamicinterpersonal psychotherapies. Journal of Counseling Psychology, 41, 449-463.

Freud, S. (1905/1953). Fragment of an Analysis of a Case of Hysteria. In J. Strachey (Ed. and Trans.), The standard edition of the complete psychological works of Sigmund Freud, Vol. 7 (pp. 3-122). London: Hogarth Press.

Freud, S. (1911/1958). Psycho-analytic notes on an autobiographical account of a case of paranoia. In J. Strachey (Ed. and Trans.), The standard edition of the complete psychological works of Sigmund Freud, Vol. 11 (pp. 9-55). London: Hogarth Press.

Glaser, B. G., \& Strauss, A. L. (1967). The discovery of grounded theory: Strategies for qualitative research. Chicago: Aldine.

Honos-Webb, L., \& Stiles, W. B. (1998). Reformulation of assimilation analysis in terms of voices. Psychotherapy, 35, 23-33.

Honos-Webb, L., Stiles, W. B., Greenberg, L. S., \& Goldman, R. (1998). Assimilation analysis of process-experiential psychotherapy: A comparison of two cases. Psychotherapy Research, 8, 264-286.

Knobloch, L. M., Endres, L. M., Stiles, W. B., \& Silberschatz, G. (2001). Convergence and divergence of themes in successful psychotherapy: An assimilation analysis. Psychotherapy, 38, 31-39.
Osatuke, K., \& Stiles, W. B. (in preparation). On different kinds of problematic internal voices: Elaboration of the assimilation model.

Stiles, W. B. (1981). Science, experience, and truth: A conversation with myself. Teaching of Psychology, 8, 227-230.

Stiles, W. B. (1993). Quality control in qualitative research. Clinical Psychology Review, 13, 593-618.

Stiles, W. B. (1997). Signs and voices: Joining a conversation in progress. British Journal of Medical Psychology, 70, 169-176.

Stiles, W. B. (1999a). Signs and voices in psychotherapy. Psychotherapy Research, 9, 1-21.

Stiles, W. B. (1999b). Signs, voices, meaning bridges, and shared experience: How talking helps. Visiting Scholar Series No. 10 (ISSN 1173-9940). Palmerston North, New Zealand: School of Psychology, Massey University.

Stiles, W. B. (2001). Assimilation of problematic experiences. Psychotherapy, 38, 462465.

Stiles, W. B. (2002). Assimilation of problematic experiences. In J. C. Norcross (Ed.), Psychotherapy relationships that work: Therapist contributions and responsiveness to patients (pp. 357-365). New York: Oxford University Press.

Stiles, W. B. (in press). Qualitative research: Evaluating the process and the product. In S. P. Llewelyn \& P. Kennedy (Eds.), Handbook of Clinical Health Psychology. London: Wiley.

Stiles, W. B., \& Angus, L. (2001). Qualitative research on clients' assimilation of problematic experiences in psychotherapy. In J. Frommer \& D. L. Rennie (Eds), Qualitative psychotherapy research: Methods and methodology (pp. 112-127). Lengerich, Germany: Pabst Science Publishers.

Stiles, W. B., Elliott, R., Llewelyn, S. P., Firth-Cozens, J. A., Margison, F. R., Shapiro, D. A., \& Hardy, G. (1990). Assimilation of problematic experiences by clients in psychotherapy. Psychotherapy, 27, 411-420.

Stiles, W. B., Meshot, C. M., Anderson, T. M., \& Sloan, W. W., Jr. (1992). Assimilation of problematic experiences: 
The case of John Jones. Psychotherapy Research, 2, 81-101.

Stiles, W. B., Morrison, L. A., Haw, S. K., Harper, H., Shapiro, D. A., \& FirthCozens, J. (1991). Longitudinal study of assimilation in exploratory psychotherapy. Psychotherapy, 28, 195-206.

Stiles, W. B., \& Osatuke, K. (2000).
Assimilation analysis. Unpublished manuscript. Department of Psychology, Miami University, Oxford, Ohio 45056

Varvin, S., \& Stiles, W. B. (1999). Emergence of severe traumatic experiences: An assimilation analysis of psychoanalytic therapy with a political refugee. Psychotherapy Research, 9, 381-404.

Table 1

Assimilation of Problematic Experiences Scale (APES)

0. Warded off/dissociated. Client is unaware of the problem; the problematic voice is silent or dissociated. Affect may be minimal, reflecting successful avoidance. Alternatively, problem may appear as somatic symptoms, acting out, or state switches.

1. Unwanted thoughts/active avoidance. Client prefers not to think about the experience. Problematic voices emerge in response to therapist interventions or external circumstances and are suppressed or avoided. Affect is intensely negative but episodic and unfocused; the connection with the content may be unclear.

2. Vague awareness/emergence. Client is aware of a problematic experience but cannot formulate the problem clearly. Problematic voice emerges into sustained awareness. Affect includes intense psychological pain-fear, sadness, anger, disgust-associated with the problematic experience.

3. Problem statement/clarification. Content includes a clear statement of a problemsomething that can be worked on. Opposing voices are differentiated and can talk about each other. Affect is negative but manageable, not panicky.

4. Understanding/insight. The problematic experience is formulated and understood in some way. Voices reach an understanding with each other (a meaning bridge). Affect may be mixed, with some unpleasant recognition but also some pleasant surprise.

5. Application/working through. The understanding is used to work on a problem. Voices work together to address problems of living. Affective tone is positive, optimistic.

6. Resourcefulness/problem solution. The formerly problematic experience is a resource, used for solving problems. Voices can be used flexibly. Affect is positive, satisfied.

7. Integration/mastery. Client automatically generalizes solutions; voices are fully integrated, serving as resources in new situations. Affect is positive or neutral (i.e., this is no longer something to get excited about).

Note. Assimilation is considered as a continuum, and intermediate levels are allowed, for example, 2.5 represents a level of assimilation half way between vague awareness/emergence (2.0) and problem statement/clarification (3.0). 